\author{
TECHNICAL NOTE
}

\title{
ON THE ECONOMICS OF ADDITIVE MANUFACTURING: EXPERIMENTAL FINDINGS
}

\begin{abstract}
Additive manufacturing offers great potential for both product and process innovation in manufacturing across a wide range of industry sectors. To date, most applications that have been reported use additive manufacturing to produce either customized parts or produce at small scale, while the volume manufacture of standard parts largely remains a conjecture. In this paper we report on a series of experiments designed to elucidate how quantity, quality and cost relate in additive manufacturing processes. Our findings show that traditional economies of scale only partially apply to additive manufacturing processes. We also identify four build failure modes and quantify their combined effect on unit cost, exposing an unusual property whereby the cost-optimal operating point occurs below maximum machine capacity utilization. Furthermore, once additive manufacturing technology is used at full capacity utilization, we find no evidence of a positive effect of increased volume on unit cost. We do, however, identify learning curve effects related to process repetition and operator experience. Based on our findings we propose a set of general characteristics of the additive manufacturing process for further testing.
\end{abstract}

Keywords: additive manufacturing; economies of scale; capacity utilization; throughput; organizational learning. 


\section{Introduction}

Additive manufacturing ( $\mathrm{AM}$ ) technology, also commonly known as 3D printing, has captured the imagination of many technology observers and manufacturing professionals. It is widely perceived as a means to rethink design, digitize manufacturing, produce to demand and customize products without cost penalty (Berman, 2012; D'Aveni, 2015; Manyika et al., 2013; Segars, 2018). Successful applications have been reported across manufacturing sectors such as hearing aids, footwear and prosthetics. A few sectors, like hearing aids, have switched their entire manufacturing process from traditional to additive manufacturing within a short timeframe (D'Aveni, 2013), sparking predictions that additive will replace traditional (tool-based) manufacturing: '(..) within the next five years we will have fully-automated, high-speed, large-quantity additive manufacturing systems that are economical even for standardized parts' (D'Aveni, 2015, p.48). AM technology is being seen as '(..) ready to emerge from its niche status and become a viable alternative to conventional manufacturing processes in an increasing number of applications' (Cohen et al., 2014, p.1).

It is worth noting that most examples of AM applications leverage the technology's ability to economically produce items at small scale, that is, to either customize products or make 'one-offs' with little or no cost penalty. Only very few examples of the application of additive manufacturing to the manufacture of standard parts have been reported; the most commonly cited one is the 3Dprinted fuel nozzle for CFM's LEAP engine that powers popular single-aisle airliners. (Annual LEAP production in 2018 was 1,118 units, which each engine containing 19 identical fuel nozzles.) CFM's justification for using AM for this application, however, is not a lower unit manufacturing cost but a weight reduction for the part that is now made of a single component, compared to 18 components previously, as well as a reduced risk of 'coking' (the build-up of fuel residue in the hot nozzle), as additive manufacturing allows for the provision of cooling channels that prevent this from happening (Shields and Carmel, 2013). The AM applications reported in the literature are generally based on the technology's specific advantages to operate without costly tooling, to deal with variety at little or no cost penalty, and to be able to design part geometries with few restrictions.

The question that has not been answered, and marks the focus of this note, is to what degree additive manufacturing is able to also displace traditional tool-based manufacturing in contexts where it has to compete on a unit cost basis alone. In the terms of Locke and Golden-Biddle (1997) this marks a 'noncoherent intertextual field', characterized by a common sense of importance yet fundamental disagreement of the economics of the AM process (Ruffo et al. 2006; Baumers et al., 2017 versus Hopkinson and Dickens 2003; Atenzi and Salmi 2012; Weller et al. 2015). 
Specifically, while some studies have suggested that unit cost levels in additive manufacturing are dependent on quantity (Ruffo et al. 2006; Baumers et al., 2017), others have argued that this relationship is entirely absent (Hopkinson and Dickens 2003; Atenzi and Salmi 2012; Weller et al. 2015). This question has substantial implications for the availability of economies of scale that determine the cost of large-scale manufacturing operations (Schmenner and Swink 1998). If additive manufacturing is to fulfil predictions of large-scale adoption (Conner et al., 2014), it too will have to exhibit a similar volume-cost relationship. This remains an area that has not yet received much attention within the operations management literature, as most research addressing operations management issues focusses on single case applications or conceptually outlining additive manufacturing's potential to disrupt existing manufacturing value chains (e.g. D'Aveni 2013, 2015; De Jong and De Bruijn 2013, Laplume et al. 2016; Weller et al. 2015; Tuck et al. 2006; Cotteleer and Joyce 2014).

In this note we thus build on studies in the engineering literature that have investigated specific cost aspects of AM technology (Alexander et al. 1998; Hopkinson and Dickens 2003; Ruffo et al. 2006; Atzeni and Salmi 2010; Atzeni et al. 2012; Rickenbacher et al. 2013; Baumers et al 2016). We report on a series of experiments that seek to elucidate the economic characteristics of the additive manufacturing process; Section \#2 reviews the theoretical foundations, before introducing our experimental setup in Section \#3. Section \#4 presents our findings, before proposing a set of general characteristics of AM processes for further testing in Section \#5.

\section{Theoretical background}

\subsection{Sources of economics of scale in traditional manufacturing}

The economics of traditional (or tool-based) manufacturing have been widely discussed (e.g., Chandler 1990; Schmenner and Swink, 1998), and are fundamental to current manufacturing practice. Processes gain 'economies of scale' when an over-proportionate cost saving is achievable by increasing the level of production. Economies of scale form a key determinant of the concept of returns to scale, which is often defined by using the standard Cobb-Douglas production function (Cobb and Douglas, 1928).

Haldi and Whitcomb (1967) systematically classify the sources of economies of scale in manufacturing, distinguishing between economies of scale in static cost relationships due to throughput-related and indivisibility-related effects, increasing returns from dynamic sources due to learning curve effects and stochastic effects relating to the reduction of process variance. 
The concept of static economies of scale reflects (1) the effect of capacity utilization, which forms some share of the possible level of machine throughput, thus resting on the relationship between machine size and unit cost, and (2), the effect of production volume due to indivisibilities resulting from a key aspect of traditional manufacturing, which is that machine operation requires a tool of some kind, and hence involves a setup cost derived from the need of changing over tools to produce a given good.

Similarly, the concept of dynamic economies of scale also stems from the indivisibility of equipment and worker, in as far as they conjointly determine the outcome. Unlike static economies of scale, however, they essentially lead to cost reductions as manufacturing activity progresses. One source of dynamic economies of scale is process repetition leading to learning curve effects, which draw on a structured cycle of defining potential problems, measuring the process, devising improvements, and verifying their effectiveness (Upton and Kim, 1998; Anand et al., 2009). Repetition of a standard process allows for the identification and eradication of unnecessary process steps and/or reduction of undesired variation, often using bundles of established 'best' practices (Shah and Ward, 2003; Schroeder et al., 2008). Having been described in the digital context as 'wetware' (Shapiro and Varian, 1999), accumulating knowledge in effect builds an asset stock residing within a manufacturing firm conferring scale-related efficiencies, either through own mass or interconnectedness with other assets (Dierickx and Cool, 1989), thereby forming an important source of competitive advantage (Peteraf and Barney, 2003).

\subsection{Defining capacity and utilization in the context of additive manufacturing}

The main production method of the additive manufacturing process is the layer-by-layer deposition of material with a geometrically defined, three-dimensional space. This is the so-called 'build volume', which defines the maximum volume within which parts can be produced. As there is a set-up cost for the additive manufacturing machine (in terms of refreshing the powder, warming up the machine, and the like), a key operational decision herein is the degree to which to fill up this build volume. The better the build volume is used, the more the fixed setup costs can be spread across parts in the build. There are two aspects of this decisions: firstly, the density how tightly the parts are packed within the build volume, to avoid wasting production space. Secondly, the operator determines the extent to which the available build space is used, as measured in terms of dispersion along the z-axis. Just as the full build volume height can be exploited, it is equally possible to limit the process to one horizontal partition. In technical terms, the operator can be said to 'commit' a fraction (or all) of the build volume to a production run. 
Choosing laser sintering (LS) technology as an illustrative example, Figure 1 illustrates three different ways of operating the additive manufacturing equipment with respect to the available machine capacity. In the case of (a), the operator seeks to build a single part. For this, he or she commits a single partition of a build height of $30 \mathrm{~mm}$, dictated by the deposited product geometry. The machine will run and stop after $30 \mathrm{~mm}$, having produced a single part in this build process. As a result, the entire fixed cost for the build will be attributed to this single part made. In case of (b), the operator also commits a build space of $z=30 \mathrm{~mm}$ (of the available $z_{\max }=330 \mathrm{~mm}$ ), after which the machine stops. However, contrary to (a), the partition is optimally packed with $n=5$ parts. Thus, the fixed cost for this build is spread across five parts, instead of only one. In case of (c), the operator commits the entire capacity available, up to the maximum build volume height. In this case, we assume that $m=11$ partitions of $n=5$ parts each can be built in the build process, and the machine will process the entire build space of $z=330 \mathrm{~mm}$. Here, the same setup cost applies as in cases (a) and (b), yet higher variable costs are incurred as the machine requires more time, energy and virgin material to complete the larger build. In the end, the fixed costs are spread across $n=55$ parts in the build process. As a result, the unit costs for producing a part vary greatly across the three cases outlined.

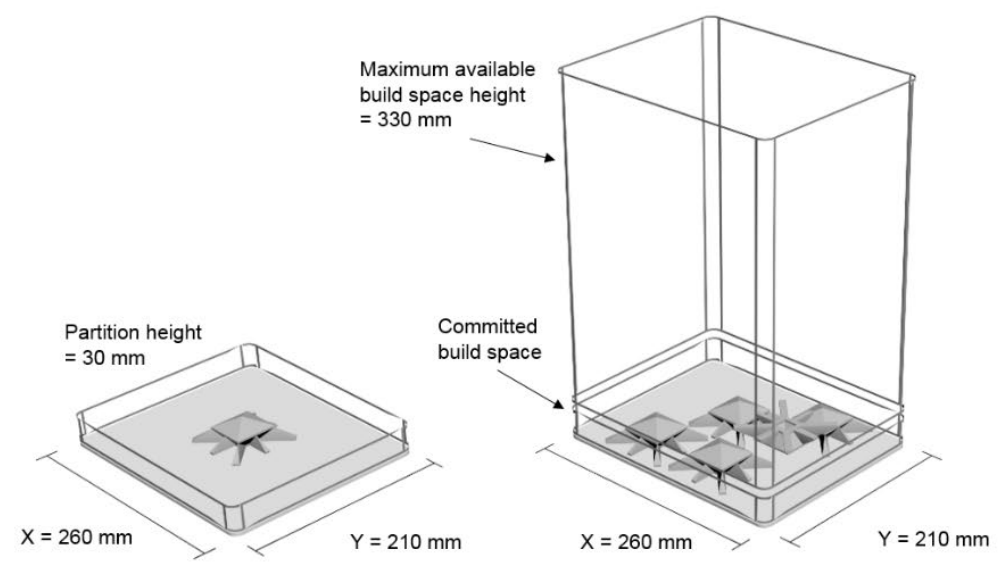

(a) (b)

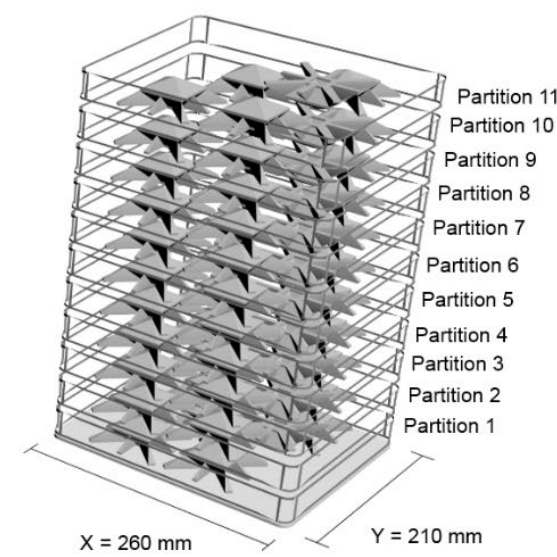

(c)

Figure 1: Build volume allocation and capacity utilization in the additive manufacturing process.

The build room allocation has a direct bearing on the notion of capacity utilization in the additive manufacturing process, which can be expressed in one of two ways. The first (and customary way in which utilization is expressed by AM operators) is to calculate the volume deposited as a share of the total committed build volume. In practice this ratio usually equates to approximately of $10 \%$ of a wellpacked build volume, which in effect means that $90 \%$ of the powder in the build space is not converted into parts but remains unused and is removed after the build. A large proportion of this powder can 
be reused, while the exact amount depends on the material used and on operator discretion. Operators will generally add a fraction of virgin material in order to prevent build quality problems (the so-called material refresh rate). Overall, this volumetric calculation is inherently useful for analyzing AM operations, but less useful in the context of the discrete manufacture of standard parts.

The second way to calculate the capacity utilization in additive manufacturing is closer to the operations management point of view: here we define capacity utilization as the number of parts in a build, as a share of the number of parts that could be built if the maximum build space was committed. In our cases above, the utilization rates would be $1.8 \%$ for (a), $9.1 \%$ for (b), and $100 \%$ for (c).

In either way, case (c) satisfies the economic 'technical efficiency' criterion, which denotes achieving given output whilst minimizing inputs (Färe and Lovell, 1978). We can thus define that additive manufacturing is used efficiently under two conditions: (1) the parts contained are optimally packed in the build volume, and (2), the build volume is used to the maximum extent possible. In turn, this conventional logic implies that not committing the full build volume to the manufacture of standard parts constitutes an inefficient use of AM technology. It should be noted that there may of course be good rood reasons for operating below technical efficiency, for example when manufacturing spare parts or prototypes. In such cases, the additional unit cost in manufacturing is offset with other savings in the value chain, for example inventory holding or tooling cost.

\subsection{Economic models of additive manufacturing operations}

The cost of AM operations, in comparison, has only recently become focus of the manufacturing engineering literature, and has not been discussed in the operations management context yet. Most of the debate is based on a model of the AM process itself; it features both conceptual papers (Petrick and Simpson, 2013; Weller et al., 2015; Mellor et al., 2014; Monzon et al., 2015; Huang et al., 2015), as well as studies that are based on empirical data (Atenzi and Salmi, 2012; Baumers et al., 2017; Hopkinson and Dickens, 2003; Ruffo et al., 2006; Ruffo and Hague, 2007). One of the first studies of the economics of AM was the generic cost model proposed by Alexander et al. (1998). In this model, costs are based on time estimates for various process steps, in particular the time required for the AM build process itself. This basic framework can be reconfigured to reflect differences in the operating principles of various AM systems and their effect on build time. However, as the cost of individual products was considered in isolation, Alexander et al. did not capture AM's nature as a parallel manufacturing technology that is capable of depositing multiple geometries at the same time in a particular build volume, which has been highlighted by Ruffo et al. (2006). 
The next evolution of AM cost models was the multi-system study by Hopkinson and Dickens (2003), focusing on the cost at high levels of capacity utilization. By inserting a large number of parts in each build process in a regular three-dimensional raster, the authors fully utilized the available build volume capacity. Hopkinson and Dickens viewed unit costs in AM as independent of production costs, resulting in a flat unit cost function, as shown in Figure 2 - suggesting the absence of a relationship between unit cost and build volume utilization. Some conclusions that have been drawn from this study are, as we will discuss below, at odds with conventional production economic thinking.

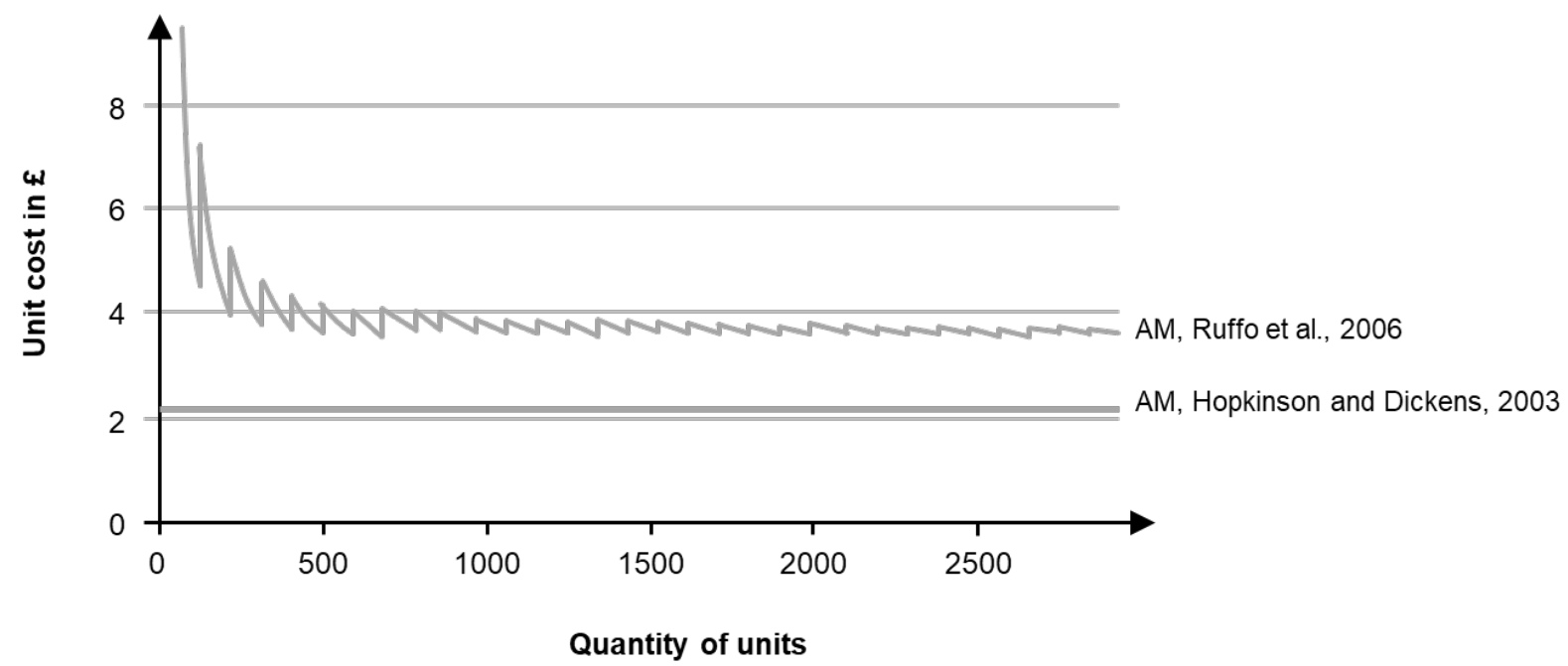

Figure 2: Constant and quantity dependent unit cost models in the literature

Ruffo et al. (2006) refined the work by Hopkinson and Dickens by adding a detailed cost structure that incorporates the impact of sub-maximal capacity utilization on unit cost, and hence establish a relationship between quantity and unit cost. Effectively, this is done by breaking the cost of the entire build operation, including the cost impact of empty build space, down to the unit cost level. As shown in Figure 2, Ruffo et al. find that higher unit costs follow from lower degrees of efficiency where the pre-committed build volume is not fully exploited. This leads to a downward sloping, jagged cost function, based on filling up such pre-committed partitions of build space. Ruffo and Hague (2007) extended this cost model by incorporating the cost impact of composing mixed builds with different part geometries.

At first glance, AM cost models such as the one proposed by Ruffo et al. (2006) indicate similarity in cost behavior between AM and conventional manufacturing processes such as injection molding, where fixed tooling costs are spread over the manufacturing quantity. However, since AM does not rely on physical tooling of any kind (Weller et al., 2015; Khajavi et al., 2015) and units of build space in AM are almost perfectly substitutable (Baumers et al. 2017), it is possible for AM users to reduce costs 
by filling empty regions of build space with other parts (Rickenbacher et al., 2013), or simply renting out spare capacity. The resulting opportunity costs give rise to concerns about technically inefficient technology usage (as defined in section 2.2. above), and in turn make it impossible to reconcile models of the type proposed by Ruffo et al. (2006) with cost-minimization as a prerequisite for cost functions.

In summary, considering that AM is heralded as a revolution in volume manufacturing ( $D^{\prime}$ Aveni, 2013, 2015; Conner et al. 2014), it is worrying that the existing literature is not conclusive as to whether economies of scale determine the relationship between quantity and cost in additive manufacturing. This highlights the need to furnish AM practitioners with realistic knowledge pertaining to the relationship between unit cost and production quantity in additive manufacturing, allowing the development of valid business cases for adoption.

\section{Experimental design}

\subsection{Additive manufacturing process map}

Laser sintering (LS) is the most common technology used in the industrial manufacturing application of AM for plastic parts. We conducted build experiments at the Centre for Additive Manufacturing at the University of Nottingham on a state-of-the-art polymeric LS system. We followed the standard work flow embedded in the LS process, shown in Figure 3. As is shown, we exclude the design phase, and consider the AM production process from having a complete design, to having produced a finished part. Process steps requiring human activity are shown in the white boxes, and the autonomous phases of the AM build process are shown in the grey boxes. Conceptualizing AM as a sequence of process steps makes it possible to accommodate events relating the origin of the digital information used and possible deviation from planned process execution. Such events enter the process flow in the form of decision nodes. We also define a boundary for our investigation, thereby excluding the cost impact of design activities in order to align this field testing to the scope of the identified empirical AM literature. Appendix A provides the full details of our experimental setup. 


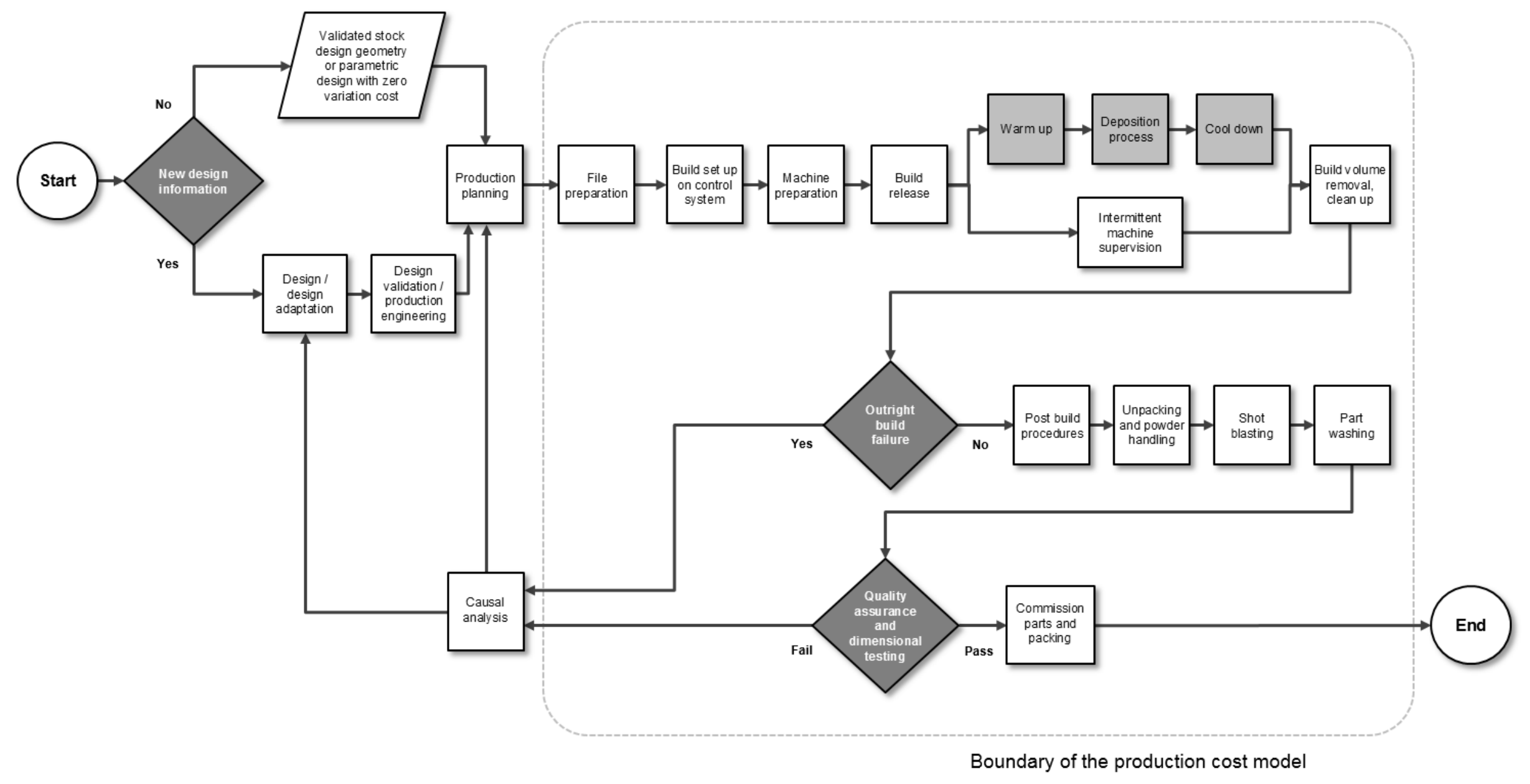

Figure 3: Process map for a polymeric laser sintering process 


\subsection{Cost data}

We include both direct and indirect cost data in our cost model to assess unit cost. We directly measured labor, material usage and energy consumption. For each build we measured the duration of each process step shown in Figure 2 using a timer and recorded it on a spreadsheet; raw material consumption was measured by weighing the raw material and the removable build container on digital scales following each build; and energy consumption was measured via a digital energy flow meter. In addition, we used a range of data from outside sources, such as technology vendors and the engineering literature, as summarized in Table 1. Raw material was purchased from the system vendor at market price, and electric energy was provided at a commercial rate.

\begin{tabular}{|c|c|c|c|c|}
\hline Cost model element & Data point & Value & Unit & Source \\
\hline \multirow{6}{*}{ Labor cost } & Full annual labor costs, novice operator & $\$ 46,015$ & /year & $\begin{array}{l}\text { University salary scales, spine } \\
\text { point } 20\end{array}$ \\
\hline & Full annual labor costs, expert operator & $\$ 62,165$ & /year & $\begin{array}{l}\text { University salary scales, spine } \\
\text { point } 30\end{array}$ \\
\hline & Working days net of holiday & 228 & days & - \\
\hline & Total hours worked per year & 1,653 & $\mathrm{~h}$ & - \\
\hline & Labor cost rate, novice operator & $\$ 27.84$ & $/ \mathrm{h}$ & - \\
\hline & Labor cost rate, expert operator & $\$ 37.61$ & $/ \mathrm{h}$ & - \\
\hline \multirow{5}{*}{ Direct cost data } & Raw material price & $\$ 56.31$ & $/ \mathrm{kg}$ & EOS (2015) \\
\hline & Material density, as deposited & 0.93 & $\mathrm{~g} / \mathrm{cm}^{3}$ & EOS (2015) \\
\hline & Energy price & $\$ 0.02$ & /MJ & $\begin{array}{l}\text { Adapted from Baumers et al. } \\
\qquad(2015)\end{array}$ \\
\hline & Fixed energy consumption per build & 25.23 & MJ & - \\
\hline & Energy consumption rate & $1,407.50$ & $\mathrm{~J} / \mathrm{s}$ & - \\
\hline \multirow{8}{*}{ Indirect cost } & Production overhead rate & $\$ 5.66$ & $/ \mathrm{h}$ & Adapted from Ruffo et al. (2006) \\
\hline & Admin overhead rate & $\$ 0.39$ & $/ \mathrm{h}$ & Adapted from Ruffo et al. (2006) \\
\hline & Machine purchase & $\$ 175,625$ & & $\begin{array}{l}\text { Adapted from Baumers et al. } \\
\qquad(2015)\end{array}$ \\
\hline & Depreciation period & 8 & years & Adapted from Ruffo et al. (2006) \\
\hline & Annual operating time & 5,000 & $\mathrm{~h}$ & Adapted from Ruffo et al. (2006) \\
\hline & $\begin{array}{l}\text { Estimated maintenance and } \\
\text { consumables }\end{array}$ & $\$ 10,645$ & /year & $\begin{array}{l}\text { Adapted from Baumers et al. } \\
\qquad(2015)\end{array}$ \\
\hline & Total machine cost rate & $\$ 6.52$ & $/ \mathrm{h}$ & - \\
\hline & Total indirect cost rate & $\$ 12.57$ & $/ \mathrm{h}$ & - \\
\hline
\end{tabular}

Table 1: Summary of data used in measuring AM production costs

Indirect costs arising from production overheads, administrative expenses, depreciation, consumables and maintenance can be allocated using activity-based costing models (Niazi et al. 2006). As shown in Table 1, we consider capital costs and overheads of the AM equipment, and excluded all costs relating to other auxiliary equipment. We apportion indirect costs over build time via an indirect 
cost rate, and sum up the labor costs of the various process steps occurring in the AM work flow to form a cost model. The cost of tooling, as a key indirect cost in conventional tool-based manufacturing, does not apply to additive manufacturing. Economies of scale in the procurement of materials, however, might be relevant for high-volume AM operations yet did not apply in our case, so were not considered.

\subsection{Results}

To inform our unit cost model the experiments were conducted at two levels of expertise: at the level of the expert operator with three years of professional experience, and at the level of novice operator. The training received by the novice operator comprised a detailed machine induction, three build demonstrations by an instructor, a practice build under the supervision of the instructor, as well as a safety briefing. In both cases, the operators received an identical assignment to execute a fixed sequence of 14 builds containing one or more instances of a test geometry. The operators were instructed to operate the LS system using default parameters and at factory settings. In cases of outright build failure with premature process termination, the operators were instructed to repeat the build. In the first series, which was undertaken by the novice operator, shown in Table 2a, we experienced two outright build failures events in experiment \#12, requiring two repetitions. In the second series, carried out by the expert, two outright build failures occurred also, as can be seen in Table $2 \mathrm{~b}$, in experiments \#7 and \#11. 


\begin{tabular}{|c|c|c|c|c|c|c|c|c|c|c|c|c|c|c|c|c|}
\hline Experiment no. & $\# 1$ & \#2 & $\# 3$ & $\# 4$ & $\# 5$ & $\# 6$ & \#7 & & $\# 8$ & $\# 9$ & $\# 10$ & - & $\# 11$ & $\# 12$ & $\# 13$ & $\# 14$ \\
\hline Type & Planned & Planned & Planned & Planned & Planned & Planned & Planned & $\begin{array}{l}\text { Repeat } \\
\text { build }\end{array}$ & Planned & Planned & Planned & $\begin{array}{l}\text { Repeat } \\
\text { build }\end{array}$ & Planned & Planned & Planned & Planned \\
\hline Capacity utilization & Full & Partial & Partial & Partial & Partial & Full & Full & Full & Full & Full & Full & Full & Full & Full & Full & Full \\
\hline $\begin{array}{l}\text { Number of test geometries } \\
\text { included }\end{array}$ & $n=5$ & $n=1$ & $\mathrm{n}=2$ & $\mathrm{n}=3$ & $n=4$ & $n=5$ & $n=5$ & $n=5$ & $n=5$ & $n=5$ & $\mathrm{n}=5$ & $n=5$ & $n=5$ & $n=5$ & $n=5$ & $n=5$ \\
\hline $\begin{array}{l}\text { Warm up time (incl. deposition of } \\
\text { blank layers and tensile bars) }\end{array}$ & $234 \mathrm{~min}$ & $204 \mathrm{~min}$ & $232 \mathrm{~min}$ & $206 \mathrm{~min}$ & $204 \mathrm{~min}$ & $234 \mathrm{~min}$ & $207 \mathrm{~min}$ & $190 \mathrm{~min}$ & $206 \mathrm{~min}$ & $234 \mathrm{~min}$ & $164 \mathrm{~min}$ & $233 \mathrm{~min}$ & $204 \mathrm{~min}$ & $199 \mathrm{~min}$ & $206 \mathrm{~min}$ & $165 \mathrm{~min}$ \\
\hline Net normal build time & $149 \mathrm{~min}$ & $106 \mathrm{~min}$ & $112 \mathrm{~min}$ & $121 \mathrm{~min}$ & $132 \mathrm{~min}$ & $149 \min$ & $15 \mathrm{~min}$ & $150 \mathrm{~min}$ & $152 \mathrm{~min}$ & $152 \mathrm{~min}$ & $70 \mathrm{~min}$ & $148 \mathrm{~min}$ & $149 \mathrm{~min}$ & $151 \mathrm{~min}$ & $150 \mathrm{~min}$ & $148 \mathrm{~min}$ \\
\hline Cool down time & $900 \mathrm{~min}$ & $600 \mathrm{~min}$ & $1020 \mathrm{~min}$ & $840 \mathrm{~min}$ & $600 \mathrm{~min}$ & $600 \mathrm{~min}$ & N/A & $840 \mathrm{~min}$ & $960 \mathrm{~min}$ & $900 \mathrm{~min}$ & N/A & $720 \mathrm{~min}$ & $960 \mathrm{~min}$ & $1080 \mathrm{~min}$ & $960 \mathrm{~min}$ & $780 \mathrm{~min}$ \\
\hline Total build time & $1283 \mathrm{~min}$ & $910 \mathrm{~min}$ & $1364 \mathrm{~min}$ & $1167 \mathrm{~min}$ & $936 \mathrm{~min}$ & $984 \mathrm{~min}$ & N/A & $1180 \mathrm{~min}$ & $1318 \mathrm{~min}$ & $1286 \mathrm{~min}$ & $\mathrm{~N} / \mathrm{A}$ & $1101 \mathrm{~min}$ & $1313 \mathrm{~min}$ & $1430 \mathrm{~min}$ & $1316 \mathrm{~min}$ & $1093 \mathrm{~min}$ \\
\hline Outright build failure & No & No & No & No & No & No & Yes & No & No & No & Yes & No & No & No & No & No \\
\hline Number of parts rejected & 0 & 0 & 0 & 0 & 0 & 0 & 0 & 1 & 2 & 0 & 0 & 0 & 1 & 0 & 0 & 0 \\
\hline Material testing failure & No & No & No & No & No & No & No & No & No & No & No & No & No & No & No & No \\
\hline Total labor content & $119 \mathrm{~min}$ & $45 \mathrm{~min}$ & $61 \mathrm{~min}$ & $49 \mathrm{~min}$ & $38 \mathrm{~min}$ & $76 \mathrm{~min}$ & N/A & $60 \mathrm{~min}$ & $61 \mathrm{~min}$ & $64 \min$ & N/A & $68 \mathrm{~min}$ & $76 \mathrm{~min}$ & $48 \mathrm{~min}$ & $66 \mathrm{~min}$ & $48 \mathrm{~min}$ \\
\hline
\end{tabular}

Table 2a: Summary of build experiments and outcomes, expert operator

\begin{tabular}{|c|c|c|c|c|c|c|c|c|c|c|c|c|c|c|c|c|}
\hline Experiment no. & $\# 1$ & \#2 & $\# 3$ & $\# 4$ & \#5 & $\# 6$ & $\# 7$ & \#8 & $\# 9$ & $\# 10$ & $\# 11$ & $\# 12$ & - & - & $\# 13$ & $\# 14$ \\
\hline Type & Planned & Planned & Planned & Planned & Planned & Planned & Planned & Planned & Planned & Planned & Planned & Planned & $\begin{array}{l}\text { Repeat } \\
\text { build }\end{array}$ & $\begin{array}{l}\text { Repeat } \\
\text { build }\end{array}$ & Planned & Planned \\
\hline Capacity utilization & Full & Partial & Partial & Partial & Partial & Full & Full & Full & Full & Full & Full & Full & Full & Full & Full & Full \\
\hline $\begin{array}{l}\text { Number of test geometries } \\
\text { included }\end{array}$ & $n=5$ & $n=1$ & $n=2$ & $n=3$ & $n=4$ & $n=5$ & $n=5$ & $n=5$ & $n=5$ & $n=5$ & $n=5$ & $n=5$ & $n=5$ & $n=5$ & $n=5$ & $n=5$ \\
\hline $\begin{array}{l}\text { Warm up time (incl. deposition of } \\
\text { blank layers and tensile bars) }\end{array}$ & $211 \mathrm{~min}$ & $212 \mathrm{~min}$ & $225 \mathrm{~min}$ & $202 \mathrm{~min}$ & $201 \mathrm{~min}$ & $213 \mathrm{~min}$ & $211 \mathrm{~min}$ & $225 \mathrm{~min}$ & $211 \mathrm{~min}$ & $271 \mathrm{~min}$ & $199 \mathrm{~min}$ & $201 \mathrm{~min}$ & $203 \mathrm{~min}$ & $205 \mathrm{~min}$ & $204 \mathrm{~min}$ & $199 \mathrm{~min}$ \\
\hline Net normal build time & $185 \mathrm{~min}$ & $157 \mathrm{~min}$ & $168 \mathrm{~min}$ & $125 \mathrm{~min}$ & $191 \mathrm{~min}$ & $204 \mathrm{~min}$ & $202 \mathrm{~min}$ & $202 \mathrm{~min}$ & $200 \mathrm{~min}$ & $201 \mathrm{~min}$ & $150 \mathrm{~min}$ & $18 \mathrm{~min}$ & $17 \mathrm{~min}$ & $151 \mathrm{~min}$ & $150 \mathrm{~min}$ & $149 \mathrm{~min}$ \\
\hline Cool down time & $600 \mathrm{~min}$ & $600 \mathrm{~min}$ & $600 \mathrm{~min}$ & $600 \mathrm{~min}$ & $600 \mathrm{~min}$ & $600 \mathrm{~min}$ & $600 \mathrm{~min}$ & $600 \mathrm{~min}$ & $600 \mathrm{~min}$ & $600 \mathrm{~min}$ & $600 \mathrm{~min}$ & N/A & N/A & $600 \mathrm{~min}$ & $600 \mathrm{~min}$ & $600 \mathrm{~min}$ \\
\hline Total build time & $996 \mathrm{~min}$ & $969 \mathrm{~min}$ & $993 \mathrm{~min}$ & $927 \mathrm{~min}$ & $992 \mathrm{~min}$ & $1017 \mathrm{~min}$ & $1013 \mathrm{~min}$ & $1027 \mathrm{~min}$ & $1011 \mathrm{~min}$ & $1072 \mathrm{~min}$ & $949 \mathrm{~min}$ & N/A & N/A & $956 \mathrm{~min}$ & $954 \mathrm{~min}$ & $948 \mathrm{~min}$ \\
\hline Outright build failure & No & No & No & No & No & No & No & No & No & No & No & Yes & Yes & No & No & No \\
\hline Number of parts rejected & 0 & 0 & 0 & 0 & 0 & 0 & 0 & 0 & 0 & 0 & 0 & 0 & 0 & 0 & 0 & 0 \\
\hline Material testing failure & No & No & No & No & No & No & No & No & No & No & No & No & No & No & No & No \\
\hline Total labor content & $177 \mathrm{~min}$ & $41 \mathrm{~min}$ & $57 \mathrm{~min}$ & $63 \mathrm{~min}$ & $84 \mathrm{~min}$ & $77 \mathrm{~min}$ & $66 \mathrm{~min}$ & $51 \mathrm{~min}$ & $54 \mathrm{~min}$ & $50 \mathrm{~min}$ & $69 \mathrm{~min}$ & N/A & N/A & $70 \mathrm{~min}$ & $55 \mathrm{~min}$ & $65 \mathrm{~min}$ \\
\hline
\end{tabular}

Table $\mathbf{2 b}$ : Summary of build experiments and outcomes, novice operator 


\section{Findings}

\subsection{Capacity and throughput effects}

We observe two effects related to capacity and throughput. Firstly, following the logic of traditional economies of scale, we predicted that filling pre-committed partitions of build space would produce a significant decrease in unit cost. In other words, if a horizontal partition in the build volume of the AM machine is not fully utilized, we expect an increase in unit cost as the fixed costs of the build are distributed across fewer parts in that build process. Ignoring the risk of build failure, for the novice operator we observe a unit cost decrease of $79.0 \%$ from $\$ 332.74$ to $\$ 69.86$ as the lowest partition $(m=1)$ is filled with $n=1$ to $n=5$ parts.

Secondly, we assessed the effect of increasing machine throughput, as illustrated in Figure 1 above. The AM operator can use up the full build volume capacity by vertically 'stacking' further fully packed partitions ( $n=5)$ within the build from $m=1$ to $m=11$. We predicted that maximizing throughput decreases cost, and our findings indicate that this is the case as we observe a unit cost reduction of $52.2 \%$, again without considering the risk of build failure. It is noteworthy that this reduction is smaller than that resulting from the filling of pre-committed build space - indicating a smaller opportunity cost penalty in this case.

These findings would suggest that static economies of scale (Haldi and Whitcomb 1967) arising from increased throughput and capacity utilization take effect in much the same way as in traditional manufacturing, despite the absence of dedicated physical tooling. We propose that in additive manufacturing there is, in fact, a two-fold relationship: for capacity utilization, unit cost reduces as pre-committed build space is filled up, while abstaining from doing so comes at a severe cost penalty. For throughput, unit cost decreases as additional build space is committed to the build operation, while refraining from allocating this extra capacity incurs a smaller cost penalty. These findings resolve the persistent disagreement in the literature as to what the cost curve of AM operation looks like: contrary to Hopkinson and Dickens (2003) and Atzeni et al. (2012), we show that total unit cost in additive manufacturing is, in general, inversely related to production quantity, up to the point where the build volume capacity is fully utilized.

\subsection{Learning curve effects}

We also investigated whether operator learning over time would result in a decrease in unit cost, by comparing the unit cost levels achieved by an expert operator versus those achieved by a novice 
operator. The first variable of interest here is the labor content, which we predict to decrease as the build is repeated. Ignoring the risk of build failure, we predicted a unit cost reduction from the first to the last build experiment at full capacity (where $n=5$ ). The results are shown in Figure 4 (see dark grey bars for the expert operator). While we observe a significant reduction of $42 \%$ in labor content from the first experiment to subsequent experiments, it can also be seen that thereafter no consistent evidence of further learning effects can be identified. The average of the expert operator's labor content was 68.6 minutes with a standard deviation of 10.2 , with no significant trend being present.

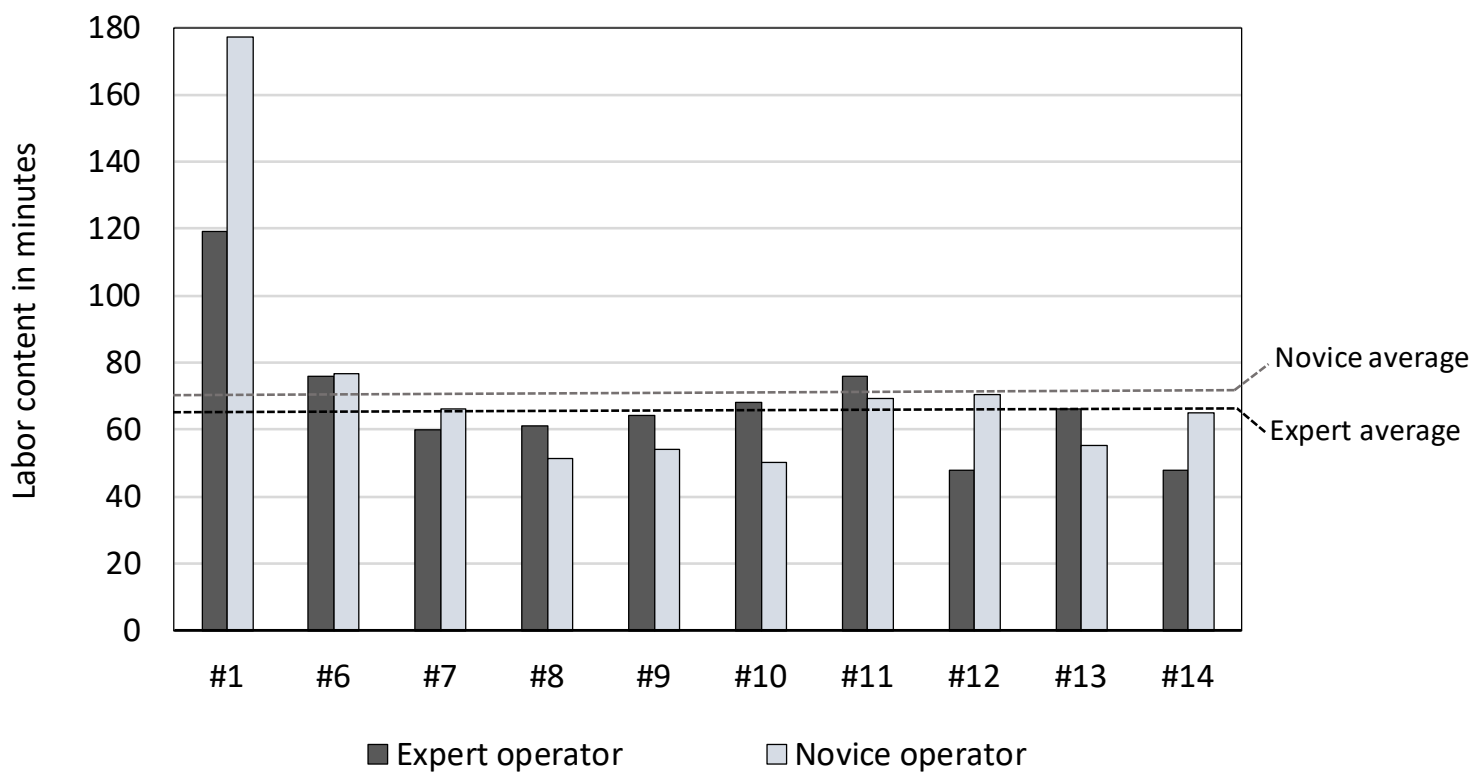

Figure 4: Labor content comparison for repeated identical experiments

This picture is replicated in the outcomes of the experiments conducted by the novice operator (see light grey bars in Figure 4): the reduction in labor content from the initial to subsequent experiments is $58.6 \%$, to an average of 73.6 minutes (and a standard deviation of 9.5 minutes). Over the course of the series, the novice operator is able to achieve a performance that is only $7.2 \%$ slower compared to the expert operator.

The second variable of interest is raw material consumption. The novice operator inserted a total of $25.57 \mathrm{~kg}$ of virgin material into the build, whereas the expert operator used only $13.51 \mathrm{~kg}$ of material to complete the identical series of build experiments. The reduction in raw material consumption indicates a real learning effect, which is the main factor responsible for the observed unit cost difference at maximum capacity utilization between the novice and the expert operators, resulting in unit cost levels of $\$ 33.42$ and $\$ 21.23$, respectively. 
Interestingly, the level of operator skill appears to have had no effect on the probability of outright build failure. This would suggest that the probability of build failure is intrinsic to the production process and does not reside in the human aspects of pre- and post-processing.

Our findings suggest that both operators not only learn and improve over time, but also that the experience of the expert operator leads to an improved performance over the novice operator. In summary, we do see initial learning curve effects that relate to both repetition of the build, as well as an effect of operator experience. Thus, our findings apprehend the potential for structured process improvement as we measured considerable variation in labor content for both operators. The scope for improvement by reducing this variation is potentially significant, evidenced by the fact that in the best case both operators demonstrated that they were able to complete the process in times $30 \%$ and $32 \%$ below their average performance, respectively.

\subsection{Build failure modes}

We observed a spectrum of build failure events in our experimental testing and identified four relevant types of failure: outright build failure, permanent part rejection, reparable part rejection, and mechanical property failure. All aspects are considered in our cost model. Table 3 summarizes the number of occurrences of each failure mode observed over the course of the build experiments. (To ensure comparability, experiments of $n<5$ were excluded).

\begin{tabular}{|c|c|c|c|c|}
\hline Failure mode & $\begin{array}{l}\# 1 \text {. Outright or } \\
\text { cascading build failure }\end{array}$ & $\begin{array}{l}\text { \#2. Permanent post- } \\
\text { build part rejection }\end{array}$ & $\begin{array}{l}\# 3 \text {. Repairable post- } \\
\text { build part rejection }\end{array}$ & $\begin{array}{l}\# 4 \text {. Mechanical } \\
\text { property or material } \\
\text { failure }\end{array}$ \\
\hline $\begin{array}{l}\text { Assumed } \\
\text { consequence }\end{array}$ & $\begin{array}{l}\text { Loss of entire build, all } \\
\text { contained parts are } \\
\text { written off }\end{array}$ & Loss of individual parts & $\begin{array}{l}\text { Remedial work to } \\
\text { affected part }\end{array}$ & $\begin{array}{l}\text { Loss of entire build, all } \\
\text { contained parts are } \\
\text { written off }\end{array}$ \\
\hline $\begin{array}{l}\text { Number of } \\
\text { occurrences }\end{array}$ & 4 events & 3 parts & 1 part & None \\
\hline Model element & $\begin{array}{l}\text { Probability of build } \\
\text { failure as a function of } \\
\text { cumulative number of } \\
\text { depositable layers }(N)\end{array}$ & $\begin{array}{l}\text { Constant probability of } \\
\text { part rejection due to } \\
\text { identical test } \\
\text { geometries }\end{array}$ & $\begin{array}{l}\text { Constant probability of } \\
\text { part rejection due to } \\
\text { identical test } \\
\text { geometries }\end{array}$ & N/A \\
\hline $\begin{array}{l}\text { Modelling } \\
\text { assumption }\end{array}$ & $\begin{array}{l}\text { Probability of build } \\
\text { failure subject to a } \\
\text { constant probability of } \\
\text { build failure per layer } \\
\left(p_{\text {constant }}\right)\end{array}$ & $\begin{array}{l}\text { Fixed probability of } \\
\text { rejection } p_{\text {non-correctable }}\end{array}$ & $\begin{array}{l}\text { Fixed probability of } \\
\text { rejection } p_{\text {correctable }}\end{array}$ & $N / A$ \\
\hline $\begin{array}{l}\text { Measured value } \\
\text { across all } \\
\text { experiments }\end{array}$ & $p_{\text {constant }}=0.016 \%$ & $p_{\text {non-correctable }}=2.500 \%$ & $p_{\text {correctable }}=0.833 \%$ & $\mathrm{~N} / \mathrm{A}$ \\
\hline
\end{tabular}

Table 3: Overview of build failure modes and occurrences 
The first, and arguably most serious, mode of process failure that we identified was outright (or cascading) build failure. Here, an unforeseen event occurs at some point during machine operation that leads to the destruction of all products contained in the build and the premature termination of the build process. These failures allow for the estimation of a variant of the Mean Time Before Failure (MTBF) metric, as defined by Hopp and Spearman (2011), providing a measure of reliability of the additive manufacturing process. In total we produced 20.346 layers in our experiments, and experienced four events of outright build failure. Based on these data one can infer the mean number of depositable layers between build failure occurrences across the experiments conducted by both operators, under the assumption that there are no systematic reasons for the occurring build failure. Empirically, on average an outright build failure should be expected every 6,244 layers, or expressed in its inverse, with a build failure probability of $p_{\text {constant }}=0.016 \%$ per layer. On a practical level, this result suggests that AM operators using the process in this configuration should expect $624 \mathrm{~mm}$ of build height as Mean Time Before Failure, which equates to more than twice the build volume height of the machine used in the experiments.

One could also define each build layer as an independent manufacturing process and assume that failures are randomly distributed with a $p_{\text {constant }}=0.016 \%$ build failure probability per layer. Under these assumptions, at a build height of $65.8 \mathrm{~mm}$ the reliability of the AM process is $90 \%$, which drops to $50 \%$ at a build height of $432.8 \mathrm{~mm}$; both figures should of course be considered in the context of the maximum build volume height of $z_{\max }=330 \mathrm{~mm}$.

The second mode of build failure relates to localized events occurring during the process and leads to the loss or rejection of an individual part. This failure mode represents the classical manufacturing defect and might occur, for example, if foreign objects are present in the build volume and disturb the deposition process, resulting in part deformation. This deviation is deemed noncorrectable and the affected part is written off. We estimate a probability of permanent rejection of $p_{\text {non-correctable }}=2.500 \%$.

The third mode of build failure occurs when an individual part is rejected, but it is possible to save the product by correcting the issue after the build has been completed. We determined part rejection by visually inspecting, as well as dimensionally measuring the manufactured test geometries. Our data indicate a probability of repairable rejection of $p_{\text {correctable }}=0.833 \%$.

The fourth mode of build failure is determined as unacceptable variation in material mechanical properties of the product post-build. This characteristic is identified through testing of tensile specimen included in each build experiment. Where the tensile specimen fails to perform in the destruction test according to standard parameters, all material used in the build must be deemed 
unusable. In practice, this is often caused by failure to sufficiently refresh the powder remaining unused in the machine. As much of the unused powder has been exposed to heating cycles in the previous build processes, it is common practice to replace between $10-50 \%$ of the powder with virgin powder, resulting in the refresh ratio mentioned in Section 2.2.

While a differentiation of failure modes is of academic interest, to the AM operator the modes are less relevant than their combined impact on unit cost. For the purpose of our study we thus combine the four build failure modes into one consolidated cost for build failure, which feeds into our cost model discussed in the following section.

\subsection{Quantity-cost relationship}

Based on our empirical findings we can plot the unit cost function's behavior across the entire range of capacity utilization, from highly inefficient configurations with a small quantity $q$ of units in the build volume, to configurations that fully exploit the available machine capacity at $q=55$. Figure 5 shows the quantity-cost relationship against $q$ test geometries contained in the build volume for both the expert and novice operators. The resulting non-monotonic 'sawtooth' unit cost curve has previously been identified by Ruffo et al. (2006) and Ruffo and Hague (2007), and shows the respective utilization within the partitions $m=1$ to 11 of the build space. Specifically, as up to $n=5$ specimen can be packed into one partition, unit cost reduces as the utilization of the partition increases. Once fully packed, the next test specimen is the sole part within the next partition $(n=1)$, which incurs a certain fixed cost. Unit cost thus oscillates while decreasing gradually as more specimens are added to the build volume.

In our experiments we encountered several build failure instances across our experiments, which combined add a further significant component to the unit cost. Without build failure, our unit cost model shows that unit cost reduces as throughput increases, with minimal unit cost at maximum machine utilization of $9.11 \%$ at $q=55$. If one includes the expected cost impact of build failure based on their likelihood of occurrence (as shown in Table 3), two findings emerge. Firstly, as expected, the average unit cost at maximum utilization $(q=55)$ for the novice operator increases by $68.2 \%$, from $\$ 33.42$ to $\$ 56.20$, with a similar increase for the expert operator. This increased cost reflects the average cost impact that the various build failure modes will induce. 


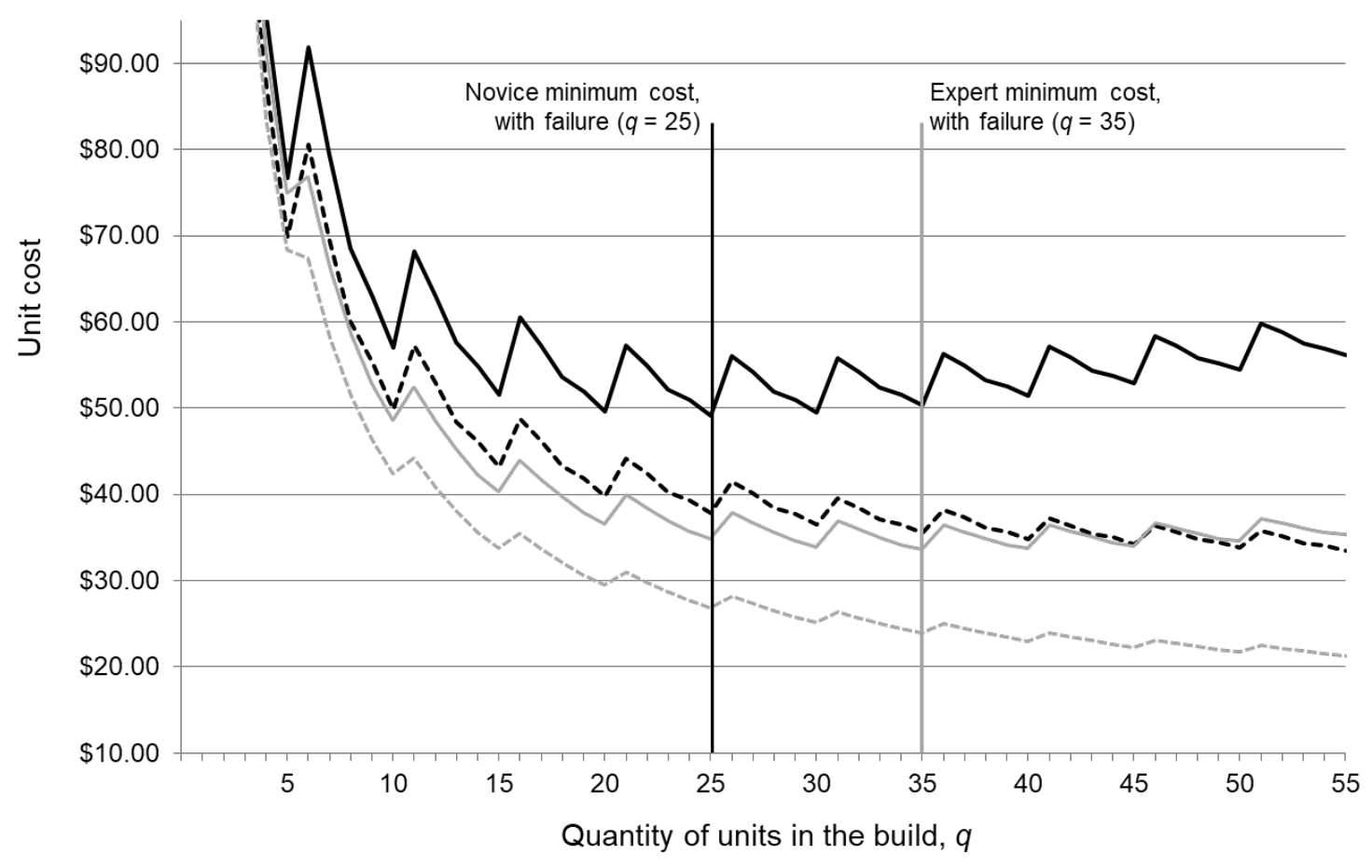

Novice unit cost, including consolidated cost of build failue
Expert unit cost, including consolidated cost of build failue

Figure 5: Relationship between cost and quantity in the additive manufacturing process

Secondly, counter to our expectations, the point of lowest-cost shifts to below maximum capacity utilization. In this case, the consolidated build failure cost outweighs the benefits of increased throughput, leading to a minimal cost configuration at $q=25$ and $q=35$ for the novice and expert operators, respectively, which is well below maximum build volume utilization of $q=55$. This produces the unusual result of a non-decreasing unit cost curve. The reason for this lies in an accumulating risk of build failure as Z-height increases: beyond $q=25$ ( $q=35$ ), for the novice operator (expert operator) the expected cost effect of failure begins outweighing the benefits accruing from the effect of increased throughput. This finding is likely influenced by the type of laser sintering machine, the material, and the test geometry used, and will require further testing to be generalizable. What emerges as a generic insight however is that the probability of build failure in the additive manufacturing process is a function of the layers deposited, since each layer constitutes an independent build step that features a probability of failure.

Finally, although not explicitly shown, Figure 5 also depicts the key difference between additive and conventional, tool-based processes like injection molding. As the build volume is fully utilized with $q=55$ parts, there is no cost advantage to producing more. In fact, the opposite is true as producing 
$q=56$ parts would require a new production cycle, thus incurring the full setup cost again. While the cost curve in conventional tool-based manufacturing decrease asymptotically as volume increases, this is not the case for additive manufacturing. The cost optimal point in additive manufacturing is the point of lowest-cost operation for one build. In traditional manufacturing, like injection molding, the unit cost keeps reducing with increasing volume.

\section{Future research}

Our findings support the hypothesis that the economics of additive manufacturing are indeed fundamentally different to traditional tool-based manufacturing, as has often been suggested (see D'Aveni 2017, 2018; Petrick and Simpson 2014; Weller et al. 2015, and others). At the same time, our experiments also show that static economies of scale apply to AM in much the same way as to traditional manufacturing - both via capacity utilization and throughput effects. Each build is best conceptualized as an individual batch with an upper capacity limit that is determined by the characteristics of the machine itself (the maximum build height), also taking into account its behavior related to build failure. Production volumes beyond the maximum batch size require an additional build process, which then constitutes a new batch, and so forth.

For each batch, or build process, the risk of build failure increases with the batch size, or in other words, the number of layers deposited. This characteristic is similar to other manufacturing processes, such as photolithographic processes used in semiconductor fabrication, where process yield is negatively affected by an increased risk of process failure associated with larger batches (see, for example Miller and Riordan, 2001). Still, a key difference applies as outright build failure in additive manufacturing is likely to affect all parts in the given build, rendering all of which defective.

Furthermore, we have empirically shown that learning curve effects are observable in the AM process flow, as both repetition and operator experience have a positive effect on performance. And while the machine operating times are prescribed by the equipment manufacturer, we have identified variation in the labor content and effectiveness of raw material usage, which highlights the potential for process improvement - analogous to any other repetitive manufacturing process.

Lastly, contrary to traditional manufacturing, the economics of additive manufacturing are shaped by the absence of physical tooling, which entails non-committal to any specific shape or design. Although not tested explicitly in this study, the most salient feature of AM is its ability to economically produce high levels of product variety (see Weller et al. 2015, Petrick and Simpson 2013, Hague et al. 2003, and others). This characteristic also engenders generality in the process, in a sense that unused 
build capacity can freely allocated to different orders, thereby generating economies of scope at (virtually) zero marginal cost.

We can combine these results into a set of key characteristics of the additive manufacturing process that we propose for further empirical testing:

1. Product variety can be produced at close to zero marginal cost;

2. Each build is a vertical batch process with a maximum batch size determined by the build volume capacity;

3. Volume-driven static economies of scale apply up to full build volume utilization, but not beyond;

4. Learning curve effects apply to both pre- and post-processing steps;

5. The risk of build failure increases with the number of layers produced.

Beyond the immediate relevance for additive manufacturing operations in practice, our investigation illustrates that our understanding of additive manufacturing processes and their performance is still rudimentary. If anything, our findings provide a strong case for operations management scholars to develop a solid understanding the performance of this new class of manufacturing processes. Specifically, we have experienced several build failure events in our testing, and have identified four distinct failure modes. Further technical research is needed to better understand the root causes for each failure mode and estimate their prevalence across additive manufacturing applications. We have assumed independence of build failure modes, yet AM practitioners often claim that both the complexity of the part geometry, as well as its position in the build cuboid, have an effect on the probability of build failure. The underlying complex relationship here so far is tacit knowledge held by additive manufacturing operators, which needs to be made explicit.

Furthermore, we have used the most commonly used industrial AM technology in our study, laser sintering, yet it is quite likely that other additive manufacturing technologies may well express different performance characteristics. Similarly, our investigation is based on a single, standalone AM machine. Further research is needed to expand our findings to multi-machine setups, which may be co-located or operate in a distributed network, and to a context where additive manufacturing is fully integrated with traditional manufacturing equipment.

In the wider context of the digitalization of manufacturing, additive manufacturing clearly represents one of the most exciting new developments in operations management and, as our findings show, provides a rich context for further investigation. We need to better understand the 
performance of AM technology as a manufacturing process, how to integrate it into the wider manufacturing system and supply chain, and the network externalities its proliferation can provide. It is time to transcend the lofty claims and bold visions that still dominate the discourse, and define the true value that additive manufacturing holds for the manufacturing sector, and the wider field of operations management.

\section{Acknowledgments}

We gratefully acknowledge the support of the EPSRC's 3DP-RDM Networking Grant EP/M017656/1, and the support of the staff at the Centre for Additive Manufacturing at the University of Nottingham. In particular we would like to thank Joseph White and Ageel Alogla for their willingness to participate in our experiments as operators. 


\section{Appendix A: Technical specification of the experiments}

The term 'additive manufacturing' is an umbrella term encompassing a variety of different technological approaches to the additive, and normally layer-by-layer, deposition of a build material. In this experiment we use laser sintering (LS), which has been noted as the most commonly adopted AM technology variants for the industrial manufacture of end-use products.

The LS process operates by feeding polymer powder into an internal build volume and then spreading it in a fine layer over the build area, which is located over a vertically moveable build platform. After preheating the build material to a suitable temperature below the melting point, a $\mathrm{CO}_{2}$ laser system is used to deflect a laser beam to selectively melt the deposited powder material. Once the exposure process in complete, the build platform indexes down by one increment, and the cycle repeats. Upon completion of all layers and sufficient cool down, the build volume can be removed from the machine for unpacking. The most commonly employed build material in laser sintering is a Polyamide 12-type powder (nylon). By selectively building up material within a bed of unprocessed powder, relatively few geometric restrictions apply to laser sintering. Additionally, support structures are not required and geometries can be distributed in the build volume in three dimensions. These aspects result in a highly parallel process, allowing the manufacture of multiple, potentially entirely unrelated, components within individual build operations.

We conducted our build experiments on a commercial laser sintering system (EOSINT P100; technical details of this laser sintering system are provided in Table A1).

\begin{tabular}{|c|c|}
\hline \multicolumn{2}{|c|}{ EOSINT P100 } \\
\hline System manufacturer & EOS GmbH \\
\hline Process type & $\mathrm{CO}_{2}$ laser, 30W \\
\hline Energy deposition & $260 / 210 / 330 \mathrm{~mm}$ \\
\hline Usable build volume size $(\mathrm{X} / \mathrm{Y} / \mathrm{Z})$ & $\mathrm{N}_{2}$ \\
\hline Process atmosphere & $\mathrm{N}_{2}$ generator, internal power supply \\
\hline $\mathrm{N}_{2}$ source & IR and resistance \\
\hline Heater type & $\sim 173$ C \\
\hline Melting temperature & PA2200, Polyamide 12-type thermoplastic \\
\hline Build material & $100 \mu \mathrm{m}$ \\
\hline Used layer thickness & Not required \\
\hline Support structures &
\end{tabular}

Table A1: Key characteristics of the EOSINT laser sintering system used 
With its ability to selectively build up material within a bed of unprocessed powder, LS is currently one of the most common forms of AM technology used in industrial production, including applications in aerospace, automotive, medical, industrial, consumer, and prototyping (Wohlers 2014). The system was operated by trained operators at factory settings configured to a layer thickness of $100 \mu \mathrm{m}$, and used standard PA2200 (nylon) build material.

Our experimental testing is based on a geometry that was modified for this research, as shown in Figure $A 1$. With a relatively large footprint in the $X / Y$ dimensions, this design was chosen to limit overall packing density to realistic levels, reaching approximately $10 \%$ utilization of the available build space at maximum packing density (Ruffo et al. 2006). Additionally, each build experiment contained a number of tensile specimens for the analysis of material properties (according to ISO 527- 2:1996).

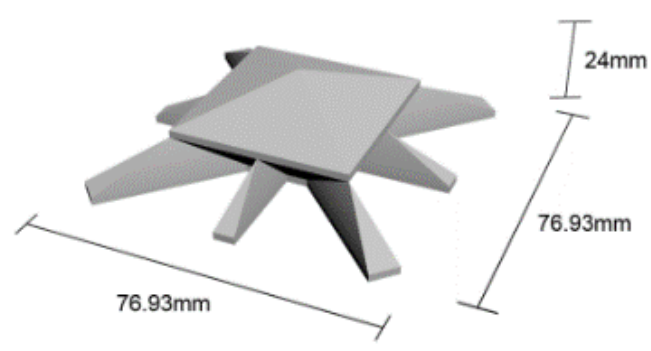

Figure A1: Test specimen

To be able to generate a sufficient number of repeat experiments to allow testing, we artificially limited the available machine capacity to a horizontal partition of the build volume with a Z-height of $30 \mathrm{~mm}$, as illustrated in Figure 1 in Section 2.2. We used a computational build volume packing algorithm employing a combined front-bottom-left and barycentric packing heuristic (Araújo et al., 2015) to populate the build space available resulting in the insertion of $n=5$ parts into each of the $m$ partitions. To infer the time and resource consumption at full machine capacity, with a Z-height of $330 \mathrm{~mm}$, we subjected our experimental results to an extrapolation procedure. This process reflected usage of the entire build space such that $m=11$ partitions were included in the build.

The algorithm used to determine the packing sequence for our $q$ parts is briefly summarized in Figure A2. Our testing comprised 28 planned experimental builds executed in two identical series, one by a novice operator and one by an expert operator. Of these, we executed 20 builds fully utilizing the allocated $30 \mathrm{~mm}$ partition of build volume space, with the automated build volume packing algorithm resulting in the insertion of five test geometries into each partition. We conducted four further builds featuring configurations with sub-maximal levels of build volume utilization $n<5$, reflecting machine operation where the available capacity is not fully used up. Due to four outright build failure events 
occurring, we conducted 32 builds overall. Including an additional build to replace rejected test geometries, we manufactured a total of 123 test geometries and 112 tensile specimens. In total, a nominal volume of $4,909 \mathrm{~cm}^{3}$ of test specimen geometry (including tensile coupons and excluding failed builds) was deposited, requiring the insertion, based on operator discretion, of $25.57 \mathrm{~kg}$ and $13.51 \mathrm{~kg}$ of virgin PA2200 powder by the novice and the expert operators, respectively. Since the amount of material present in the machine before and after our experiments was unknown and material insertion was determined by the operators, these values should be seen as approximations of material requirements. In terms of the constructed failure model, we continued monitoring the build activity after the conclusion of our experiment by the novice and expert operators, recording the number of successfully deposited layers in the following ten builds or up to the next failure (whichever occurred first).

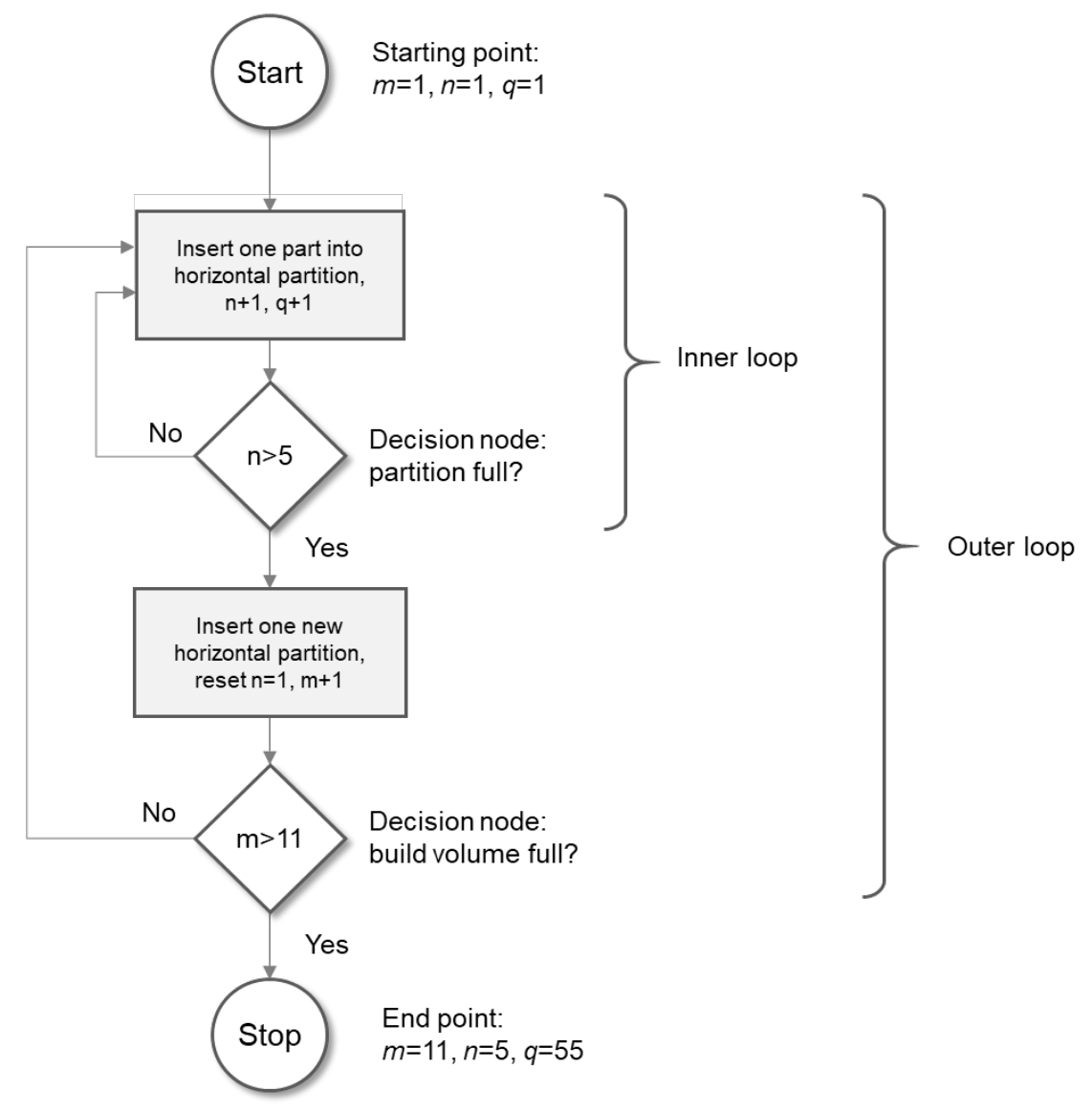

Figure A2: Build volume packing sequence as a nested loop algorithm. 


\section{References}

Alexander, P., Allen, S. and Dutta, D., 1998. Part orientation and build cost determination in layered manufacturing. Computer-Aided Design, 30(5), pp.343-356.

Anand, G., Ward, P.T., Tatikonda, M.V. and Schilling, D.A., 2009. Dynamic capabilities through continuous improvement infrastructure. Journal of Operations Management, 27(6), pp.444-461.

Araújo, L.J.P., Özcan, E., Atkin, J.A., Baumers, M., Tuck, C. and Hague, R., 2015. Toward better build volume packing in additive manufacturing: Classification of existing problems and benchmarks. Proceedings of the Solid Freeform Fabrication (SFF) Symposium. The University of Texas at Austin.

Atzeni, E., luliano, L., Minetola, P. and Salmi, A., 2010. Redesign and cost estimation of rapid manufactured plastic parts. Rapid Prototyping Journal, 16(5), pp.308-317.

Atzeni, E. and Salmi, A., 2012. Economics of additive manufacturing for end-usable metal parts. The International Journal of Advanced Manufacturing Technology, 62(9-12), pp.1147-1155.

Baumers, M., Dickens, P., Tuck, C. and Hague, R., 2016. The cost of additive manufacturing: machine productivity, economies of scale and technology-push. Technological Forecasting and Social Change, 102, pp.193-201.

Baumers, M., Beltrametti, L., Gasparre, A. and Hague, R., 2017. Informing additive manufacturing technology adoption: total cost and the impact of capacity utilisation. International Journal of Production Research, 55(23), pp.1-14.

Berman, B., 2012. 3-D printing: The new industrial revolution. Business Horizons, 55(2), pp.155-162.

Cobb, C.W. and Douglas, P.H., 1928. A theory of production. The American Economic Review, 18(1), pp.139-165.

Cohen, D., Sargeant, M., Somers, K., 2014. 3D printing takes shape. McKinsey Quarterly, https://www.mckinsey.com/business-functions/operations/our-insights/3-d-printing-takes-shape (Accessed 14/06/2019)

Conner, B.P., Manogharan, G.P., Martof, A.N., Rodomsky, L.M., Rodomsky, C.M., Jordan, D.C. and Limperos, J.W., 2014. Making sense of 3-D printing: Creating a map of additive manufacturing products and services. Additive Manufacturing, 1-4, pp.64-76.

Cotteleer, M. and Joyce, J., 2014. 3D opportunity: Additive manufacturing paths to performance, innovation, and growth. Deloitte Review, 14, pp. 5-19.

De Jong, J.P. and De Bruijn, E., 2013. Innovation lessons from 3-D printing. MIT Sloan Management Review, 54(2), p.43.

D'Aveni, R., 2013. 3-D printing will change the world. Harvard Business Review, 91(3), pp.34-35.

D'Aveni, R., 2015. The 3-D printing revolution. Harvard Business Review, 93(5), pp.40-48

D'Aveni, R., 2017. Choosing scope over focus. MIT Sloan Management Review 58(4), pp.22-26

D'Aveni, R., 2018. The Pan-industrial revolution: How new manufacturing titans will transform the world. Houghton Mifflin.

Dierickx, I. and Cool, K., 1989. Asset stock accumulation and sustainability of competitive advantage. Management Science, 35(12), pp.1504-1511.

EOS, 2015. Corporate website. [Online], available from: www.eos.info/en (Accessed: 24/09/2015).

Färe, R. and Lovell, C.K., 1978. Measuring the technical efficiency of production. Journal of Economic Theory, 19(1), pp.150-162. 
Hague, R., Campbell, I. and Dickens, P., 2003. Implications on design of rapid manufacturing. Proceedings of the Institution of Mechanical Engineers, Part C: Journal of Mechanical Engineering Science, 217(1), pp.25-30.

Haldi, J. and Whitcomb, D., 1967. Economies of scale in industrial plants. The Journal of Political Economy, 75(4, Part 1), pp.373-385.

Hopkinson, N. and Dickens, P., 2003. Analysis of rapid manufacturing-using layer manufacturing processes for production. Proceedings of the Institution of Mechanical Engineers, Part C: Journal of Mechanical Engineering Science, 217(1), pp.31-39.

Hopkinson, N., Hague, R. and Dickens, P. eds., 2006. Rapid manufacturing: An industrial revolution for the digital age. John Wiley \& Sons.

Hopp, W.J. and Spearman, M.L., 2011. Factory physics, $3^{\text {rd }}$ edition. Long Grove: Waveland Press.

Huang, Y., Leu, M.C., Mazumder, J. and Donmez, A., 2015. Additive manufacturing: Current state, future potential, gaps and needs, and recommendations. Journal of Manufacturing Science and Engineering, 137(1), p.014001-1-11.

Laplume, A.O., Petersen, B. and Pearce, J.M., 2016. Global value chains from a 3D printing perspective. Journal of International Business Studies, 47(5), pp.595-609.

Locke, K., Golden-Biddle, K.J., 1997. Constructing opportunities for contribution: Structuring intertextual coherence and 'problematizing' in organizational studies. Academy of Management Journal: 40(5), pp.1023-1062.

Manyika, J., Chui, M., Bughin, J., Dobbs, R., Bisson, P., Marrs, A., 2013. Disruptive technologies: Advances that will transform life, business, and the global economy. McKinsey Global Institute San Francisco, CA.

Mellor, S., Hao, L. and Zhang, D., 2014. Additive manufacturing: A framework for implementation. International Journal of Production Economics, 149, pp.194-201.

Miller, R.B. and Riordan, W.C., 2001. Unit level predicted yield: A method of identifying high defect density die at wafer sort. IEEE Test Conference (pp. 1118-1127).

Niazi, A., Dai, J.S., Balabani, S. and Seneviratne, L., 2006. Product cost estimation: Technique classification and methodology review. Journal of Manufacturing Science and Engineering, 128(2), pp.563-575.

Peteraf, M.A. and Barney, J.B., 2003. Unraveling the resource-based tangle. Managerial and Decision Economics, 24(4), pp.309-323.

Petrick, I.J. and Simpson, T.W., 2013. 3D printing disrupts manufacturing: how economies of one create new rules of competition. Research-Technology Management, 56(6), pp.12-16.

Rickenbacher, L., Spierings, A. and Wegener, K., 2013. An integrated cost-model for selective laser melting (SLM). Rapid Prototyping Journal, 19(3), pp.208-214.

Ruffo, M. and Hague, R., 2007. Cost estimation for rapid manufacturing simultaneous production of mixed components using laser sintering. Proceedings of the Institution of Mechanical Engineers, Part B: Journal of Engineering Manufacture, 221(11), pp.1585-1591.

Ruffo, M., Tuck, C. and Hague, R., 2006. Cost estimation for rapid manufacturing-laser sintering production for low to medium volumes. Proceedings of the Institution of Mechanical Engineers, Part B: Journal of Engineering Manufacture, 220(9), pp.1417-1427.

Schmenner, R.W. and Swink, M.L., 1998. On theory in operations management. Journal of Operations Management, 17(1), pp.97-113. 
Schroeder, R.G., Linderman, K., Liedtke, C. and Choo, A.S., 2008. Six Sigma: Definition and underlying theory. Journal of Operations Management, 26(4), pp.536-554.

Segars, A.H., 2018. Seven Technologies Remaking the World. MIT Sloan Management Review: An Executive Guide, March.

Shah, R. and Ward, P.T., 2003. Lean manufacturing: Context, practice bundles, and performance. Journal of Operations Management, 21(2), pp.129-149.

Shapiro, C. and Varian, H.R., 1999. Information rules: A strategic guide to the network economy. Harvard Business Press.

Shields, M., Carmel, J., 2013. Turbofan engine technology upgrades: How should suppliers react? Avascent report. http://www.avascent.com/2013/09/turbofan-engine-technology-upgradessuppliers-react/ (accessed 2 October 2018).

Son, Y.K., 1991. A cost estimation model for advanced manufacturing systems. The International Journal of Production Research, 29(3), pp.441-452.

Tuck, C., Hague, R. and Burns, N., 2006. Rapid manufacturing: impact on supply chain methodologies and practice. International Journal of Services and Operations Management, 3(1), pp.1-22.

Tuck, C.J., Hague, R.J., Ruffo, M., Ransley, M. and Adams, P., 2008. Rapid manufacturing facilitated customization. International Journal of Computer Integrated Manufacturing, 21(3), pp.245-258.

Upton, D.M. and Kim, B., 1998. Alternative methods of learning and process improvement in manufacturing. Journal of Operations Management, 16(1), pp.1-20.

Varian, H.R., 1984. The nonparametric approach to production analysis. Econometrica: Journal of the Econometric Society, pp.579-597.

Weller, C., Kleer, R. and Piller, F.T., 2015. Economic implications of 3D printing: Market structure models in light of additive manufacturing revisited. International Journal of Production Economics, 164, pp.43-56.

Wohlers, T., 2014. Wohlers report 2014. Fort Collins: Wohlers Associates. 